\title{
Article \\ Effect of the Passive Ultrasonic Irrigation and the Apical Diameter Size on the Debridement Efficacy of Infected Root Canals: A Multivariate Statistical Assessment of Histological Data
}

\author{
Marcela Alcota ${ }^{1}$, Jimena Osorio ${ }^{1}$, Claudia Díaz ${ }^{1}$, Ana Ortega-Pinto ${ }^{2}{ }^{\mathbb{D}}$, Cristián Peñafiel $^{2}$, Juan C. Rivera ${ }^{3}$, \\ Daniela Salazar ${ }^{1}$, Germán Manríquez ${ }^{4,5,6, *}$ and Fermín E. González ${ }^{1,7,8, * \mathbb{D}}$
}

1 Department of Conservative Dentistry, Faculty of Dentistry, University of Chile, Santiago 8380492, Chile; malcota@u.uchile.cl (M.A.); jimeosoriom@gmail.com (J.O.); cdiaz@odontologia.uchile.cl (C.D.); dsalazar@odontologia.uchile.cl (D.S.)

2 Department of Pathology and Oral Medicine, Faculty of Dentistry, University of Chile, Santiago 8380492, Chile; aortega@odontologia.uchile.cl (A.O.-P.); cpenafiel@odontologia.uchile.cl (C.P.)

3 Private Practice, Cali 760042, Colombia; juancamiloriverac@hotmail.com

4 Centre for Quantitative Analysis in Dental Anthropology (CA2), Faculty of Dentistry, University of Chile, Santiago 8380492, Chile

check for updates

Citation: Alcota, M.; Osorio, J.;

Díaz, C.; Ortega-Pinto, A.;

Peñafiel, C.; Rivera, J.C.; Salazar, D.; Manríquez, G.; González, F.E. Effect of the Passive Ultrasonic Irrigation and the Apical Diameter Size on the Debridement Efficacy of Infected Root Canals: A Multivariate Statistical Assessment of Histological Data. Appl. Sci. 2021, 11, 7495. https://doi.org/10.3390/app11167495

Academic Editors: Ricardo Castro Alves, José João Mendes and Ana Cristina Mano Azul

Received: 28 June 2021

Accepted: 9 August 2021

Published: 16 August 2021

Publisher's Note: MDPI stays neutral with regard to jurisdictional claims in published maps and institutional affiliations.

Copyright: (c) 2021 by the authors. Licensee MDPI, Basel, Switzerland. This article is an open access article distributed under the terms and conditions of the Creative Commons Attribution (CC BY) license (https:// creativecommons.org/licenses/by/ $4.0 /)$
5 Dental Sciences Research Institute, Faculty of Dentistry, University of Chile, Santiago 8380492, Chile

6 Department of Anthropology, Faculty of Social Sciences, University of Chile, Santiago 8380492, Chile

7 Laboratory of Experimental Immunology \& Cancer, Faculty of Dentistry, University of Chile, Santiago 8380492, Chile

8 Millennium Institute on Immunology and Immunotherapy, Faculty of Medicine, University of Chile, Santiago 8380453, Chile

* Correspondence: gmanriquezs@odontologia.uchile.cl (G.M.); fgonzalez@uchile.cl (F.E.G.)

Abstract: The removal of necrotic and vital pulp substrates and microorganisms and their toxins from the root canal system (RCS) has been found to be the basis for a successful endodontic treatment. In this study, our aim was to evaluate the effect of passive ultrasonic irrigation (PUI) on the elimination of the organic remnant tissue from infected, narrow and curved mandibular root canals during their instrumentation. For this purpose, mesiobuccal canals from mandibular first molars were instrumented with the RaCe rotary system, using PUI activation or conventional irrigation (CI) and two apical diameters (\#25 and \#35). The root canal cleanness of the samples was evaluated by microscopy and using a modified Langeland's ordinal scale. Parametric and non-parametric statistical analyses and principal coordinates analysis (PCOA) of the samples were performed. When PUI was used, there was a significant reduction of the organic remnant in the apical enlargement of 25 at $2 \mathrm{~mm}$ from the apex $(p<0.001)$. After pooling the groups, regardless of the depth of the observation ( 2 and $4 \mathrm{~mm}$ from the apex), the pair \#35 + PUI vs. \#25 + CI showed statistically significant differences $(p<0.001)$. The effect of PUI explained $65 \%$ of the overall variance when compared with the CI samples. The use of PUI reduced the organic material of narrow infected and curved root canals with an apical enlargement of \#25 and \#35. When PUI is not used, a biomechanical instrumentation up to a diameter $\geq \# 35$ is recommended.

Keywords: passive ultrasonic irrigation; apical enlargement; organic remnant

\section{Introduction}

Conventionally, the cleaning of the root canal system (RCS) is done with a chemicalmechanical preparation using endodontic instruments and irrigating the area profusely with disinfecting chemical solutions [1]. The basis for a successful endodontic treatment is the complete removal from the RCS [2] of both necrotic and vital pulp substrates, together with microorganisms and their toxins. In this context, the complexity of the 
morphology of the RCS makes their complete mechanical debridement a major challenge for clinicians. It has been shown that over $35 \%$ of the RCS surface remains untouched by endodontic instruments after instrumentation [3,4], highlighting the importance of efficient instrumentation and irrigation to ensure the proper chemical debridement and disinfection of the RCS.

One of the most important factors for the clinical success of an endodontic treatment is the proper preparation of the apical third of the root canal. Inappropriate preparation and disinfection of this portion can lead to the persistence of organic remnants (i.e., microorganisms and necrotic tissue). These, in turn, may cause periapical inflammation, disfavouring tissue repair and resulting in the consequent failure of the treatment, especially in non-vital and infected teeth $[5,6]$.

When analysing the amount of enlargement needed in the preparation of the apical portion of infected root canals, several aspects must be considered, such as the action of the irrigant solutions [5,7], the bacterial penetration into dentinal tubules $[5,8,9]$, and the irregular and complex morphology of the RCS $[5,7,10,11]$.

It has been demonstrated that the higher the apical diameter the better disinfection of root canals, mainly because of the mechanical elimination of contaminated dentin and the penetration of the irrigant solution in the apical region $[5,12]$. Despite great advances in mechanised instrumentation systems and their alloys, in complex anatomies it is difficult to reach high apical diameters during instrumentation. Although these last-generation instruments may allow for higher diameter coverage, they may also lead to the risk of procedural mistakes, such as transportations and foramen deformation, among others. In these situations, the effect of the irrigant solution becomes fundamental in order to remove debris, dissolve remnant tissue and act as a lubricant $[4,10,11]$.

On the other hand, as far as the irrigation of the root canal is concerned, it has been shown that PUI is more effective than CI for removing organic tissue, because of its ability to disintegrate more bacteria and dentin debris [13-17]. Recently, Lee et al. (2019) have demonstrated that a higher amount of organic remnant is eliminated using PUI during the ex vivo preparation of vital root canals when using instruments with low apical diameters [18]. However, they state that their conclusions are not completely applicable to infected root canals. Thus, our hypothesis states that PUI enhances the removal of dentin debris and organic remnant during the preparation of infected root canals, especially when instruments with low apical diameters are used.

The objective of this study was to evaluate the effect of PUI on the removal of the organic remnant tissue from narrow, infected and curved root canals during their instrumentation with apical enlargements of \#25 and \#35.

\section{Materials and Methods}

\subsection{Sample Collection}

Fifty-three mandibular molars were selected according to the following selection criteria:

Inclusion criteria: (i) recently extracted non-vital and infected mandibular molars;

(ii) non-endodontically treated teeth; (iii) diagnosis of symptomatic apical periodontitis and chronic or acute apical abscesses; (iv) root canals with moderate curvature (between $10^{\circ}$ and $25^{\circ}$ ) according to Schneider's criteria [19]; and (v) narrow and permeable mesiobuccal root canals of mandibular molars.

In order to measure the curvature by Schneider's criteria, X-rays of the roots were taken in the same direction of the curve [19]. For this purpose, the extracted teeth were positioned on a $\mathrm{N}^{\circ} 2 \mathrm{X}$-ray intraoral film with the crown-apical axis of the mesiobuccal root parallel to the film with the central ray tangent to the curve of the root. To determine the permeability of the root canals, we used canals where a \#10 K-file was the highest instrument which reached patency.

Exclusion criteria: teeth with previous history of endodontic access or treatment; and fused, incompletely developed and straight or fractured roots. 


\subsection{Study Groups}

The selected root canals with moderate curvatures were randomly divided into two groups: Group 1 consisting of 24 root canals instrumented by using RaCe rotary files (FKG Dentaire SA, La Chaux-de-Fonds, Switzerland) and using PUI; and group 2 consisting of 24 root canals instrumented with $\mathrm{RaCe}$ rotary files and using $\mathrm{CI}$ with syringes as control. Five non-instrumented root canals were used for assessing histological intraobserver error calibration. Groups 1 and 2 were further divided in two subgroups: $1 \mathrm{~A}$, in which an instrument with an apical diameter of $\# 25(\mathrm{n}=10)$ was used; $1 \mathrm{~B}$, in which an instrument with an apical diameter of \#35 ( $\mathrm{n}=10)$ was used; $2 \mathrm{~A}$, in which an instrument with an apical diameter of $\# 25(n=12)$ was used; and $2 B$, in which an instrument with an apical diameter of \#35 ( $n=12)$ was used.

\subsection{Instrumentation Procedures}

Immediately after extraction, the teeth were kept in a 10\% formalin buffer solution for a week. The teeth were allocated into different groups by a randomised and alternate assignment following the sequence $1 \mathrm{~A}, 1 \mathrm{~B}, 2 \mathrm{~A}$, and $2 \mathrm{~B}$. Instrumentation procedures were performed by two experimented and calibrated operators (J.O. and C.D.). Teeth were endodontically accessed and patency achieved with a size $10 \mathrm{~K}$-file (Dentsply Maillefer, Ballaigues, Switzerland). Coronal pre-flaring was accomplished with a size $20 \mathrm{~K}$-file (Dentsply Maillefer) and PreRaCe file \#30/0.06 taper to obtain straight line access to the canal and eliminate coronal curvature. A size $10 \mathrm{~K}$-file (Dentsply Maillefer, Ballaigues, Switzerland) was passively introduced into each canal until its tip was visible at the apical foramen. The working length (WL) was established by subtracting $1 \mathrm{~mm}$ from the previous distance. The root canal preparation was performed using RaCe file \#15/0.04 taper and RaCe file \#25/0.04 taper for subgroups 1A y 2A, and an additional RaCe file \#35/0.04 taper for subgroups $1 \mathrm{~B}$ y $2 \mathrm{~B}$. During the instrumentation procedure, the root canals were irrigated before and after each instrument with $0.5 \mathrm{~mL}$ of $\mathrm{NaOCl} 5.25 \%$, using a $27 \mathrm{G}$ needle (Monoject) and positive pressure irrigation at $\mathrm{WL}-2 \mathrm{~mm}$, followed by a final wash with $0.5 \mathrm{~mL}$ of EDTA for $2 \mathrm{~min}$ and $1 \mathrm{~mL} \mathrm{NaOCl} 5.25 \%$.

For group 1, the root canal preparation was finished using the same final protocol irrigation together with PUI. The file was passively inserted at WL $-2 \mathrm{~mm}$ and activated for $30 \mathrm{~s}$ with a Varios 560 multifunctional ultrasonic scaler (NSK, Kanuma, Japan) with 2.5 power and ultrasonic tips with a diameter of \#20. Attempts were made to maintain the file centred in the canal during activation. Each file was used and discarded after five samples. For group 2, the root canal preparation was finished using the same final protocol irrigation using CI with syringes. The RaCe rotary files were operated in a continuous rotation motion at $350 \mathrm{rpm}$ and a torque of $2 \mathrm{Ncm}$ by an electric motor model Endo-Mate TC (NSK, Kanuma, Japan).

\subsection{Histological Procedures and Organic Remnant Analysis}

After instrumentation, the teeth were fixed in $10 \%$ formalin, demineralised in a $5 \% \mathrm{Ni}$ tric Acid solution for $48 \mathrm{hrs}$ and then moved to an Ana Morse solution for two weeks. Decalcified roots were included in paraffin and then perpendicular crosscut slices (5-micrometers thickness) were obtained. Four slides with 2-4 cuts each were prepared at 2 and $4 \mathrm{~mm}$ from the apex, stained with haematoxylin and eosin (H\&E) and stored for further analysis. Therefore, at least eight cuts were made at both depths in each sample and the most representative section was chosen for further histological analysis.

During histological procedures, two teeth were lost in groups $1 \mathrm{~A}$ and $1 \mathrm{~B}$, so the final sample size for these groups was ten teeth each. The root transversal samples were analysed with a light microscope Leica DM5000 (Leica Microsystems, Wetzlar, Germany) at different magnifications. Images were captured using LAS EZ 3.2.0. photo capture software. The root canal cleanness was evaluated by a single blinded and calibrated observer (A.O.) with a 0 to 3 score scale, similar to that used by Langeland et al. $[20,21]$ in which we eliminated score 4 (i.e., the count of inflammatory cells in samples from animal models, which is not the case in this study). The score used was: 0 to refer to a root canal with organic remnant, 
predentin or debris in all the lumen of the histological sample; 1 to refer to a root canal with organic remnant in most parts of the lumen; 2 to refer to a relatively wide root canal with organic remnant in the margins; and 3 to refer to an absolutely clean root canal (Figure 1).
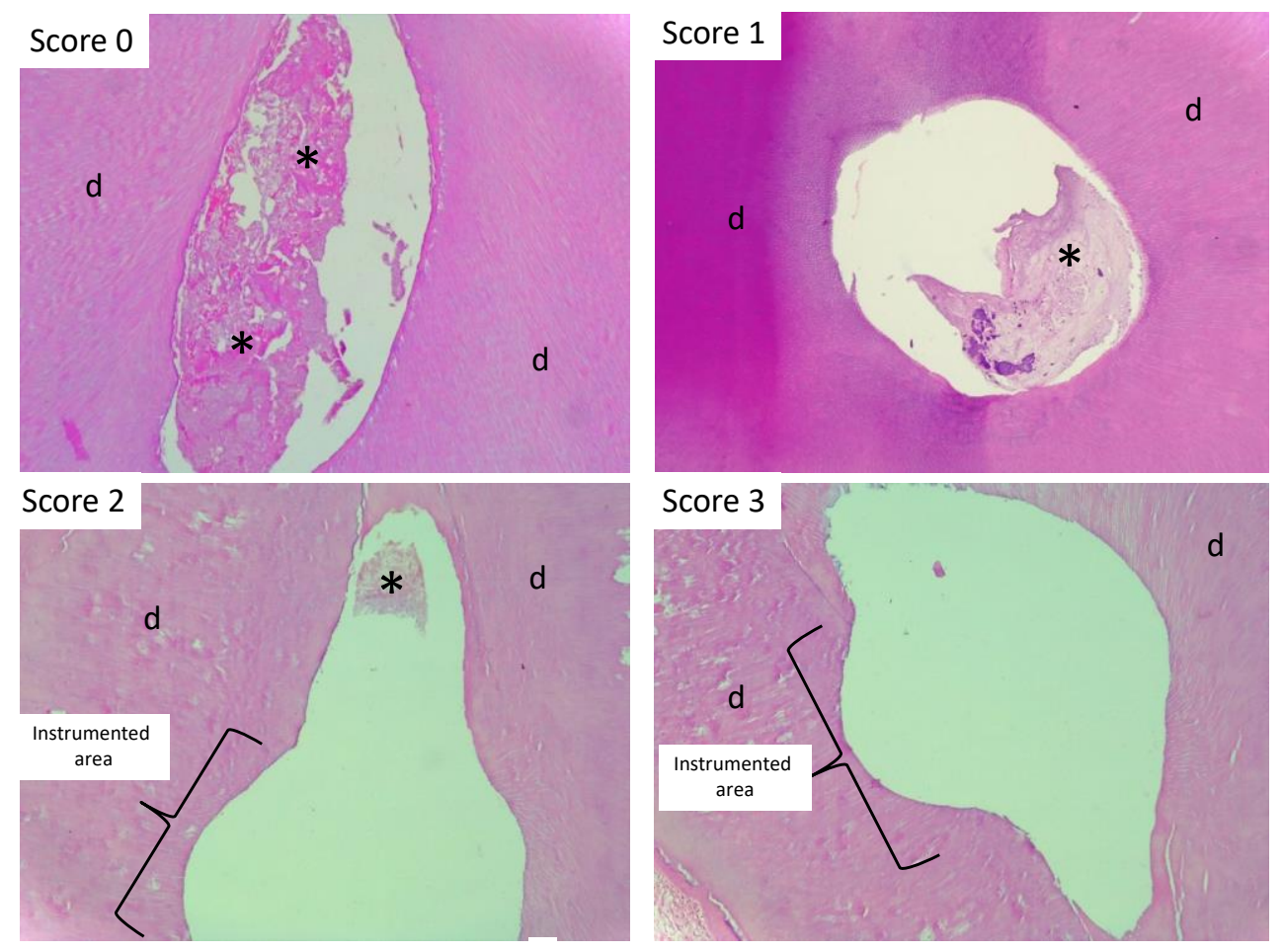

Figure 1. Representative images of the score scale used for the evaluation of root canal cleanness (based on Langeland et al.). Score 0: Root canal with organic remnant, predentin or debris in every histological sample. Score 1: Root canal with organic remnant in most part of the lumen. Score 2: Relatively wide root canal with organic remnant in the margins. Score 3: Absolutely clean root canal. H\&E staining. Original magnification: $10 \times{ }^{*}=$ organic remnant. $\mathrm{d}=$ dentin.

\subsection{Statistical Analyses}

In order to test the hypothesis explaining the effect of the variables under study (i.e., PUI vs. CI removal of organic remnant), statistical analyses were carried out as follows: (i) Epps-Singleton (ES) test for equal distributions to assess the effect of each diameter separately and Kruskal-Wallis test for equal medians to test the diameter effect as a whole, (ii) Mann-Whitney pairwise test to test the diameter of the instrument on the canal cleanness score observed after biomechanical instrumentation (BIns), and (iii) Principal Coordinate Analysis to assess the overall effect of PUI compared to CI, using a one-way Analysis of Similarities (ANOSIM) as a post-hoc test. The rationale behind using an ES test instead of the widely used Kolmogorov-Smirnov (KS) two-sample test lies in the greater statistical power of the first test when compared with the second [22]. Regarding the ANOSIM post-hoc test, it is the non-parametric version of the one-way ANOVA for ranked ordinal data [23]. All the analyses were run in PAST 4.06b statistical program [24].

\section{Results}

\subsection{Effect of PUI on the Organic Remnant Removal Regarding the Instrumentation with Different Diameters}

When the instrumentation procedures were analysed separately, only the instrumentation with \#25 at $2 \mathrm{~mm}$ crosscut from the apex showed statistically significant differences between the PUI and CI samples (1A vs. 2A) (Figure 2 and Table 1). After pooling the \#25 and \#35 groups, regardless of the depth of the observation (crosscuts of 2 and $4 \mathrm{~mm}$ from the apex), the pair \#25 + CI vs. \#35 + PUI showed statistically significant differences (group $2 \mathrm{~A}$ vs. group 1B) (Figure 2 and Table 1). 
BIns 25-2 *

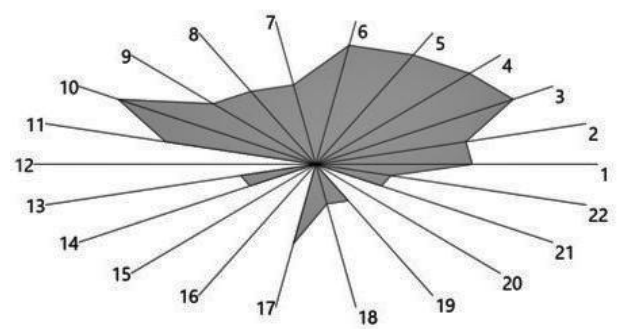

BIns 35-2

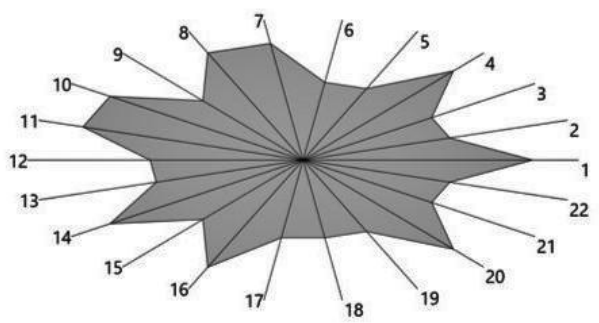

Blns 25-2 + Blns 25-4*

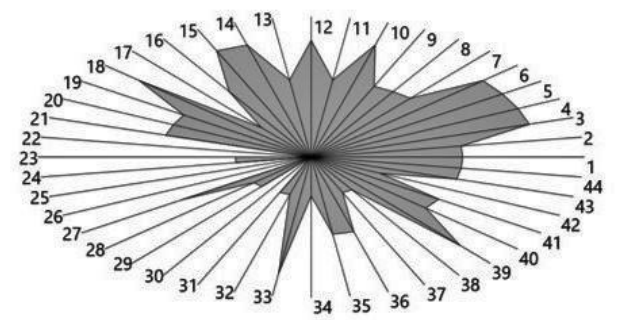

BIns 25-4

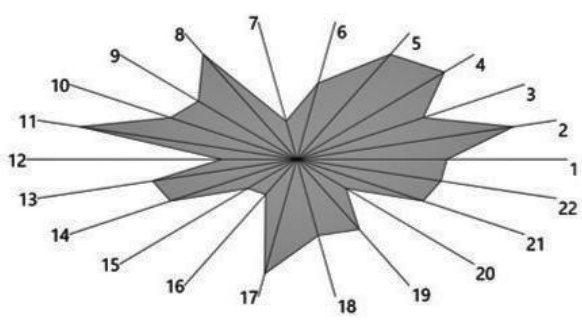

Blns 35-4

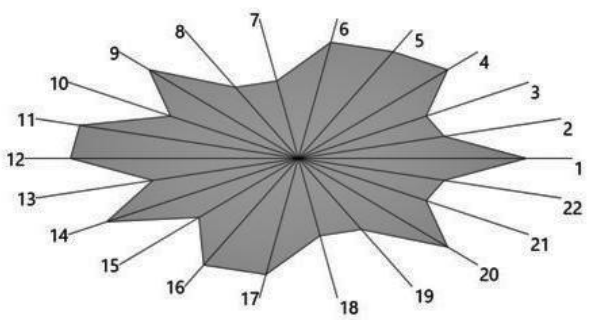

Blns 35-2 + Blns 35-4

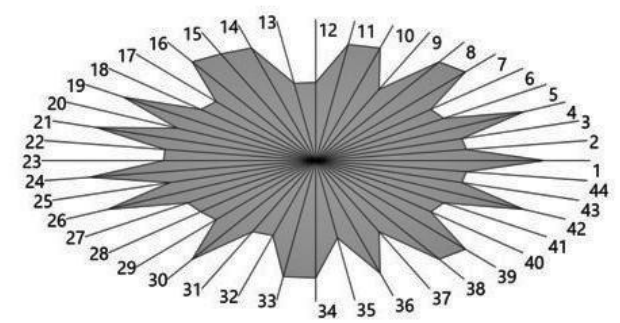

Figure 2. Frequency of cleanness scores registered after analysing the root transversal samples used in this study. In single diameter radar plots (first two rows) teeth 1-10 = PIU, and teeth 11-22 = CI. In pooled diameter radar plots (last row) teeth 1-20 = PIU, and teeth 21-44 = CI. * Statistically significant differences when comparing PIU and CI scores $(p<0.001$, for details see Table 1). Bins = Biomechanical instrumentation (\#-mm from apex).

Table 1. Effect of PUI on debris removal regarding the diameter of the instrument used during biomechanical instrumentation.

\begin{tabular}{ccc}
\hline $\begin{array}{c}\text { Instrument Size (\#-mm from } \\
\text { Apex) }\end{array}$ & Epps-Singleton W2 & $p$ Value (Same Distance) \\
\hline $25-2$ & 43.58 & $7.84 \times 10^{-9}$ \\
\hline $25-4$ & 1.39 & 0.8460 \\
\hline $35-2$ & 0.40 & 0.9823 \\
\hline $35-4$ & $3.24 \times 10^{-16}$ & 1 \\
\hline $25(2,4)$ & 21.10 & $3 \times 10^{-4}$ \\
\hline $35(2,4)$ & 0.22 & 0.9944 \\
\hline
\end{tabular}

A representative histological section, at $2 \mathrm{~mm}$ from the apex, is shown in Figure 3 , with apical enlargement of \#25 without PUI, where the presence of organic remnants is evident, (Figure 3A,B) vs. an apical histological section with enlargement of \#25 with PUI, where the organic remnant is starkly reduced (Figure $3 C, D)$. 

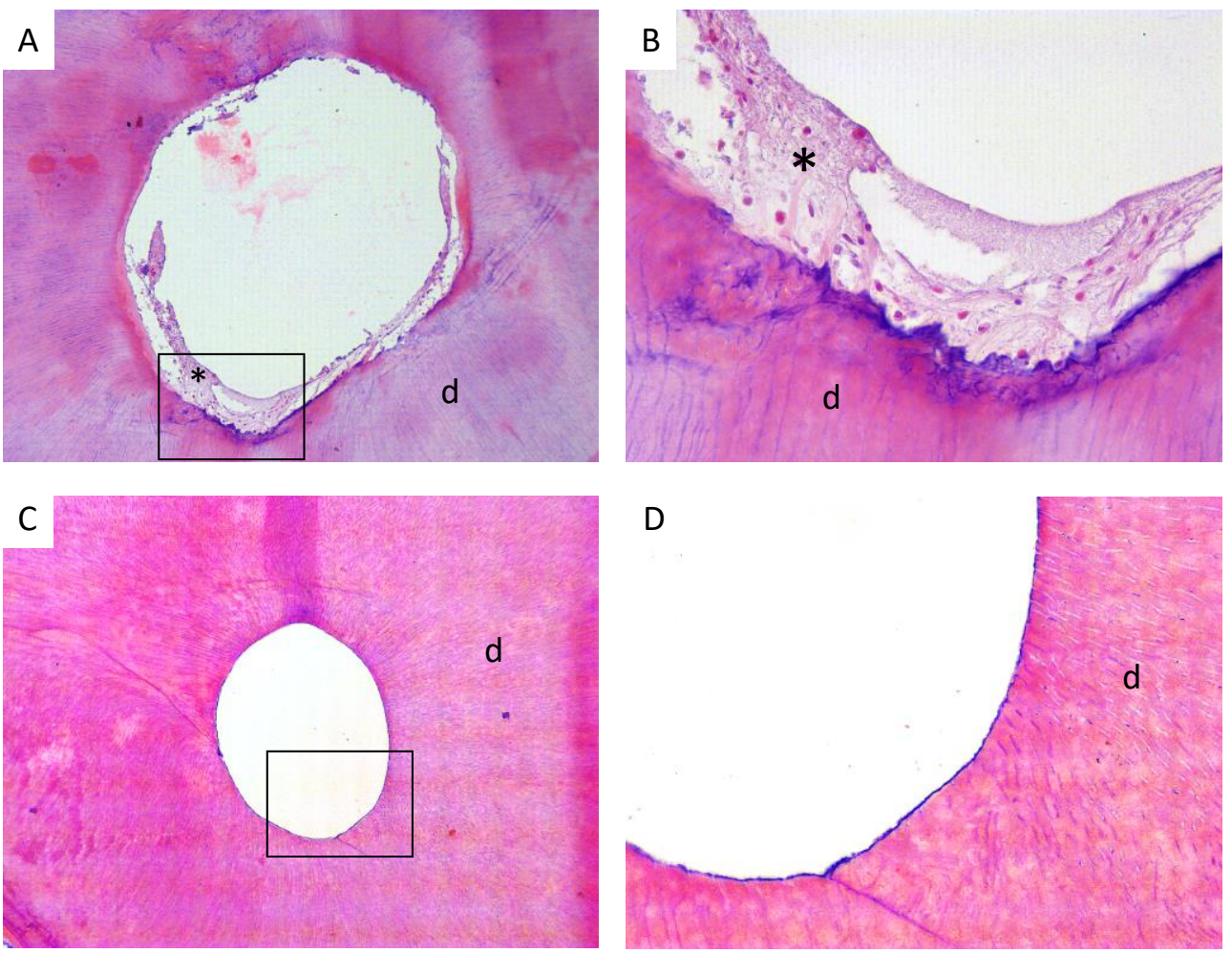

Figure 3. Representative images, at $2 \mathrm{~mm}$ from the apex, of root canals instrumented with RaCe system with and without PUI. (A,B): Root canals instrumented with RaCe system \#25 without PUI. Organic remnant is observed adjacent to the walls of the apical canal. (C,D): Apical canals instrumented with RaCe system \#25 with PUI. The walls of the apical canal are observed without organic remnants. H\&E staining. Magnification: $(A, C), 10 \times(B, D), 40 \times{ }^{*}=$ organic remnant. $d=$ dentin.

\subsection{Effect of PUI and the Diameter of Endodontic Instruments for Biomechanical Removal on} Teeth Cleanness

Compared with the control samples, the cleanness of the teeth under the effect of PUI and endodontic instrumentation was significantly improved (Kruskal-Wallis test for equal medians: $\mathrm{H}\left(\mathrm{Chi}^{2}\right)=11.52$, Hc (tie corrected $)=13.62$, p (same) $\left.=0.003474\right)$.

Regarding the endodontic instrumentation, the observed differences are mainly explained by the diameter of the operational device (\#35 vs. \#25), independently from the depth of the observation (2 vs. $4 \mathrm{~mm}$ from the apex) (Table 2). In addition, in the histological sections obtained from the samples of this study, we observed that none of the studied root canals were completely free from debris readily accumulated in the isthmus of mesial root canals (Figure 4).

Table 2. Effect of the diameter of the instrument on the canal cleanness score observed after biomechanical instrumentation (Mann-Whitney pairwise test, Bonferroni corrected $\mathrm{p}$ values). BIns = Biomechanical instrumentation (\#-mm from apex).

\begin{tabular}{ccc}
\hline & BIns 25-2 & BIns 25-4 \\
\hline BIns 25-4 & 0.9076 & \\
\hline BIns 35-2 & 0.03814 & 0.5247 \\
\hline BIns 35-4 & 0.01547 & 0.1988 \\
\hline
\end{tabular}



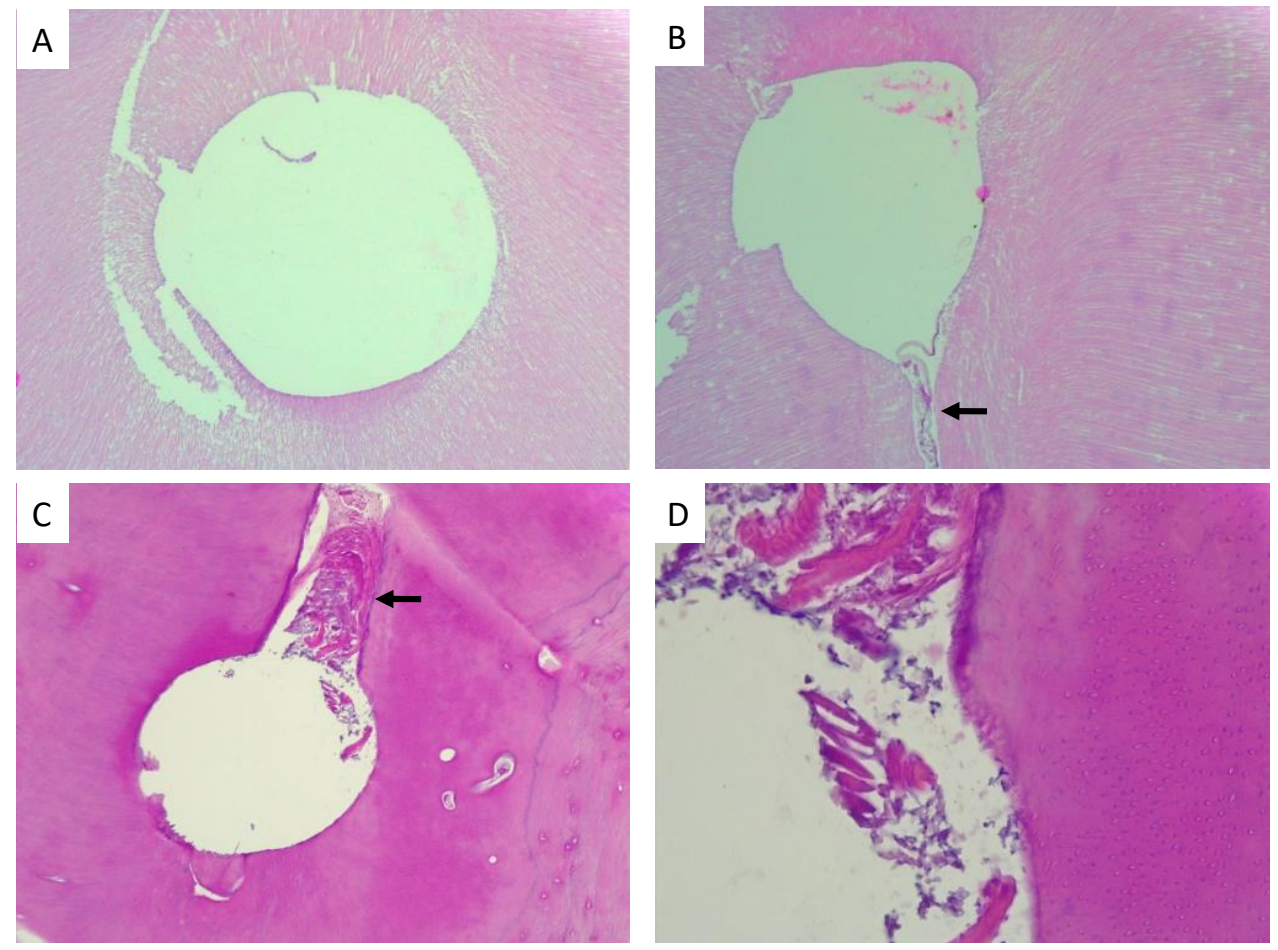

Figure 4. Representative images, at $2 \mathrm{~mm}$ from the apex, of roots canals prepared with different instrument diameters. (A): Root canal instrumented with \#35 without PUI. Magnification 10×. (B): We can observe the remains of detritus in the isthmus after instrumentation (black arrow). Magnification $10 \times$. (C): Root canal instrumented in a single pole with lime RaCe \#25. We can observe the remains of detritus in the polar opposite (black arrow) Magnification 10×. (D): Approach of the previous case. Magnification $40 \times$.

After applying a PCoA to the ordinal raw data obtained by the Langeland's ordinal scale for teeth cleanness, the effect of PUI explained $64.9 \%$ of the overall variance when compared with the control (conventional irrigation, CI). The percentage of PCo 1 expected by chance variance was below what was observed, implying a statistically significant difference between the PUI and CI samples (i.e., $52 \%$ vs. $64.9 \%$, respectively, after a brokenstick model) (Figure 5). These results were corroborated by a one-way ANOSIM post-hoc test $(\mathrm{R}=0.3383, p$ (same) $=0.0005$, mean ranks $=95.7-134.8$, using Manhattan similarity index after 9.999 permutations).

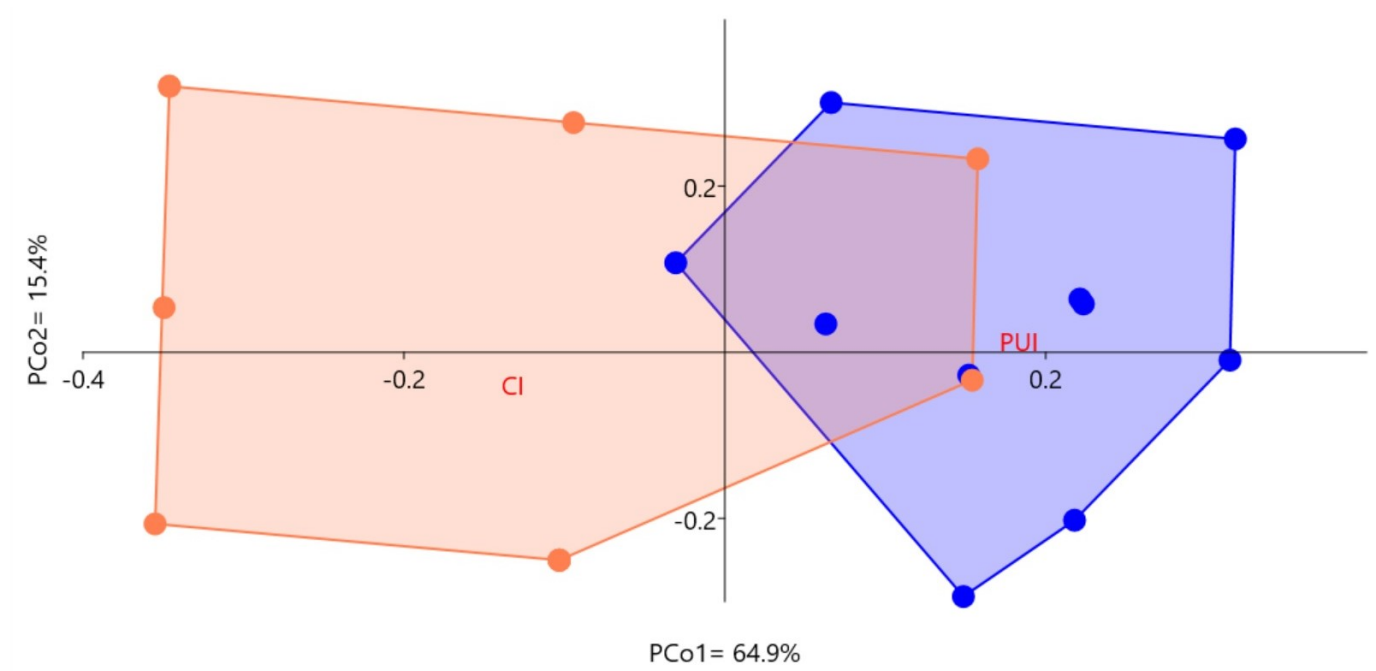

Figure 5. Principal Coordinate Analysis (PCoA) of the raw data. Visualization of the dissimilarities of the ordinal raw data 
used in this study after assigning a location to each observation in a low-dimensional space represented by the Principal Coordinate axes, where PCo1 $>$ PCo2 $>\ldots>$ PCoZ.

Finally, Table 3 is a summary of our findings and it compares the elimination of organic material after the biomechanical rotary instrumentation of narrow, infected and curved root canals with or without PUI and apical enlargements of \#25 and \#35.

Table 3. Summary of the experimental design to assess the effect of three relevant variables on RCS cleanness: (1) Distance from the apex (depth); (2) Irrigation system (PUI vs. Conventional syringes); and (3) Diameter of the instrument used during biomechanical instrumentation (\#25 vs. \#35). A" +" sign indicates the presence of a significant effect of each of the analysed variables; its absence means that there are no differences between them. $\mathrm{RCS}=$ Root canal system; $\mathrm{CI}=$ Conventional irrigation .

\begin{tabular}{ccccc}
\multicolumn{2}{c}{ Irrigation System } & \multicolumn{2}{c}{$\begin{array}{c}\text { Diameter of the Instrument } \\
\text { (RaCe 0.04 Taper) }\end{array}$} \\
\cline { 2 - 5 } & PUI & CI & \#25 & $\# 35$ \\
\hline & + & - & - & + \\
\hline
\end{tabular}

\section{Discussion}

We compared the effect of PUI on the efficacy of the elimination of organic material remaining into infected, narrow and moderated curved mandibular root canals after their instrumentation using the RaCe rotary files 0.04 taper with apical enlargements of \#25 and \#35, following an instrumentation protocol similar to the one we used in clinical practice.

Our results show that when PUI was combined with the RaCe rotary system instrumentation, there was no difference in the elimination of organic material between groups $1 \mathrm{~A}$ and $1 \mathrm{~B}$ (with apical enlargements of \#25 and \#35, respectively). Our results agree with the study of Lee et al. who compared different apical diameters with and without PUI [18]. They found that PUI reduces remnant pulp tissues in canals to small preparations. However, in the present study we performed an instrumentation and irrigation protocol which is closer to the real clinical practice than the one used by Lee et al., who used a single file protocol. In addition, we used infected and moderate curved root canals instead of vital pulp teeth. Regarding the latter, there is a consensus that PUI is more effective than traditional syringe irrigation, removing more efficiently the organic tissue, planktonic bacteria and dentine debris from the root canal. These phenomena could be explained because the ultrasound creates a higher speed and flow volume of the irrigant in the canal during irrigation, thereby eliminating more debris, producing less apical packing, allowing better access of the chemical product to accessory canals and even causing a flush effect to be produced by ultrasound but not manual irrigation [3,13].

On the other hand, in our study when the instrumentation was performed without PUI in apical enlargements of \#25 and \#35, the difference in the elimination of organic material was significant, with a pronounced reduction in the $2 \mathrm{~B}$ group (with apical enlargement of \#35) compared with 2A group (with apical enlargement of \#25). This is in agreement with several studies regarding apical enlargement that establish a directly proportional relationship between the increase of last instrument diameter and the reduction of organic and bacterial remaining [5-7,10,15,21,25-28]. In fact, during canal preparation, apical size has been crucial in defining the successful debridement of the RCS because the penetration of the irrigant into the apical one-third of the canal and the removal of debris depend on the final size of the instrument used in the canals; so, an increase in the apical preparation size significantly enhances the root canal disinfection $[10,25]$.

In addition, several studies have shown the relevance not only of the apical preparation but also of the taper in the instrumentation of the apical one-third of root canals. Regarding this, a previous study by Plotino et al. (2014) showed that the cleanliness of the apical canal walls was better when the apical preparation was performed after a basic preparation of a 
size \#25/0.06 taper, irrespective of the technique used to perform the apical preparation [29]. Srikanth et al. (2015) showed that for proper penetration of irrigants, removal of debris and the smear layer from the apical third region, the enlargement to \#30 file size is adequate when the suitable coronal taper is achieved. A more recent study by $\mathrm{Xu}$ et al. (2018) determined that when the apical size increased to \#40, the remnant debris significantly decreased in the mesial roots of mandibular first molars [30].

In our study, we observed an important reduction of the organic remnant when using PUI during apical preparations up to \#25 (1A vs. 2A groups). In addition, the amount of organic remnant in group 1A was comparable with what we observed in group 2B. In other words, using PUI instead of CI improves the \#25-diameter efficiency as well as the \#35-diameter with a CI protocol. This is particularly relevant when the clinician is instrumenting complex root canal morphology (e.g., mesiobuccal roots of upper molars), where it often becomes impossible to reach apical diameters of \#35 or higher without transportation and/or perforation risk. Additionally, we found a cleaner area of the samples studied at $4 \mathrm{~mm}$ from the apex with and without PUI, compared to the area at $2 \mathrm{~mm}$ from the apex which had the highest content of detritus. This coincides with Paqué et al. (2005), who found an increase in the amount of debris towards the apical region using RaCe without PUI [31]. We believe that this may be explained by an increased flow, and therefore, greater solvent action of hypochlorite in this region, at $4 \mathrm{~mm}$ from the apex.

It is important to note that none of the root canals from the four groups analysed in this study was completely free from hard-tissue debris, with debris readily accumulated in the isthmus of mesial root canals (Figures 2 and 3). In this regard, we consider that all rotary instrumentations must be complemented by a thorough manual instrumentation in order to achieve optimal debridement, because those systems tend to keep a centred positioned inside the canal, failing to reach both internal and external pole of the canal. This, together with activation of sodium hypochlorite during instrumentation, could more effectively eliminate the presence of organic debris within the canals, especially from areas which are difficult to access or inaccessible by mechanized instrumentation.

One of the limitations of this study was the use of an ordinal scale to assess a change which is intrinsically infinitesimal, like the quantity of organic remnant found in RCS after instrumentation. This limitation can be overcome by calculating and comparing the surface occupied by debridement in the root canal of the control and experimental histological samples. A further development of this study will be to evaluate the debridement efficacy of infected root canals using EndoActivator (Dentsply Maillefer) or XP-Endo Finisher (FKG Dentaire) compared with PUI.

\section{Conclusions}

This work adds evidence regarding the clinical treatment of infected and curved root canals, showing that the use of PUI becomes fundamental when the augmentation up to \#35 or \#40 of apical diameter is difficult, if not impossible, because of the presence of curves or little amount of dentinal wall in the apical third of the root canal. Therefore, we consider that clinicians should incorporate PUI as part of their regular therapeutic strategy, since it helps to remove pulp tissue from isthmus and flattened root canals from vital teeth. Also, in cases of infected root canals, it might have an antibacterial effect by disorganizing biofilm into root canals, thus significantly improving the prognosis of these treatments.

Author Contributions: Conceptualization, M.A., G.M. and F.E.G.; Methodology, M.A., G.M. and F.E.G.; Validation, J.O., C.D., A.O.-P. and C.P.; Formal Analysis, G.M. and F.E.G.; Investigation, J.O., C.D., A.O.-P. and C.P.; Resources, M.A., J.O., C.D., A.O.-P., G.M. and F.E.G.; Data Curation, J.O., C.D. and A.O.-P.; Writing-Original Draft Preparation, M.A., J.O., C.D. and F.E.G.; Writing-Review \& Editing, M.A., J.O., A.O.-P., C.P., J.C.R., D.S., G.M. and F.E.G.; Visualization, A.O.-P., G.M. and F.E.G.; Supervision, M.A. and F.E.G.; Project Administration, M.A. and F.E.G.; Funding Acquisition, M.A., G.M. and F.E.G. All authors have read and agreed to the published version of the manuscript. 
Funding: This work was partially supported by CONICYT, Programa de Investigación Asociativa Anillos en Ciencia y Tecnología ACT N-096 grant (G.M.) and the Faculty of Dentistry, University of Chile, FIOUCH 17-007 grant (F.E.G.). The APC was funded by the Faculty of Dentistry, University of Chile.

Institutional Review Board Statement: The present study was performed in agreement with the guidelines of the Declaration of Helsinki and approved by the Ethical Committee of the Faculty of Dentistry, University of Chile (Pri-ODO 15479).

Informed Consent Statement: Written consent from patients was waived because the teeth used in the study were samples that had been discarded after extraction either in public dental services or in the Dental Clinic of the Faculty of Dentistry, University of Chile. However, all patients had given oral consent for further use of the discarded samples.

Data Availability Statement: Data obtained from this study is not available publicly. Information regarding these data should be requested to the corresponding authors.

Acknowledgments: The rotary instruments used in this study were donated by FKG Dentaire SA. We thank Juan Fernández from the Language and Translation services, Faculty of Dentistry, Universidad de Chile and Claudia Trajtemberg, MPhil University of Cambridge, UK, for kindly proofreading and checking the spelling and grammar of this manuscript.

Conflicts of Interest: The authors declare that there is no conflict of interest regarding the publication of this article.

\section{References}

1. Cesario, F.; Hungaro Duarte, M.A.; Duque, J.A.; Alcalde, M.P.; de Andrade, F.B.; Reis So, M.V.; De Vasconcelos, B.C.; Vivan, R.R. Comparisons by microcomputed tomography of the efficiency of different irrigation techniques for removing dentinal debris from artificial grooves. J. Conserv. Dent. 2018, 21, 383-387. [CrossRef]

2. Dioguardi, M.; Di Gioia, G.; Illuzzi, G.; Laneve, E.; Cocco, A.; Troiano, G. Endodontic irrigants: Different methods to improve efficacy and related problems. Eur. J. Dent. 2018, 12, 459-466. [CrossRef] [PubMed]

3. Mozo, S.; Llena, C.; Forner, L. Review of ultrasonic irrigation in endodontics: Increasing action of irrigating solutions. Med. Oral Patol. Oral Cir. Bucal. 2012, 17, e512-e516. [CrossRef]

4. Kumar, T.; Dhillon, J.S.; Gill, G.S.; Singla, R.; Rani, S.; Dhillon, M. An in vitro comparison of the antimicrobial efficacy of positive pressure and negative pressure irrigation techniques in root canals infected with Enterococcus faecalis. J. Conserv. Dent. 2018, 21, 438-442. [CrossRef]

5. Baugh, D.; Wallace, J. The role of apical instrumentation in root canal treatment: A review of the literature. J. Endod. 2005, 31, 333-340. [CrossRef] [PubMed]

6. Tan, B.T.; Messer, H.H. The effect of instrument type and preflaring on apical file size determination. Int. Endod. J. 2002, 35, 752-758. [CrossRef] [PubMed]

7. Siqueira, J.F., Jr.; Lima, K.C.; Magalhaes, F.A.; Lopes, H.P.; de Uzeda, M. Mechanical reduction of the bacterial population in the root canal by three instrumentation techniques. J. Endod. 1999, 25, 332-335. [CrossRef]

8. Waltimo, T.M.; Orstavik, D.; Siren, E.K.; Haapasalo, M.P. In vitro yeast infection of human dentin. J. Endod. 2000, 26, 207-209. [CrossRef]

9. Berkiten, M.; Okar, I.; Berkiten, R. In vitro study of the penetration of Streptococcus sanguis and Prevotella intermedia strains into human dentinal tubules. J. Endod. 2000, 26, 236-239. [CrossRef]

10. Srikanth, P.; Krishna, A.G.; Srinivas, S.; Reddy, E.S.; Battu, S.; Aravelli, S. Minimal Apical Enlargement for Penetration of Irrigants to the Apical Third of Root Canal System: A Scanning Electron Microscope Study. J. Int. Oral Health 2015, 7, 92-96.

11. Reddy, J.M.; Latha, P.; Gowda, B.; Manvikar, V.; Vijayalaxmi, D.B.; Ponangi, K.C. Smear layer and debris removal using manual $\mathrm{Ni}$-Ti files compared with rotary Protaper Ni-Ti files-An In-Vitro SEM study. J. Int. Oral Health 2014, 6, 89-94. [PubMed]

12. Brunson, M.; Heilborn, C.; Johnson, D.J.; Cohenca, N. Effect of apical preparation size and preparation taper on irrigant volume delivered by using negative pressure irrigation system. J. Endod. 2010, 36, 721-724. [CrossRef] [PubMed]

13. van der Sluis, L.W.; Versluis, M.; Wu, M.K.; Wesselink, P.R. Passive ultrasonic irrigation of the root canal: A review of the literature. Int. Endod. J. 2007, 40, 415-426. [CrossRef] [PubMed]

14. van der Sluis, L.W.; Shemesh, H.; Wu, M.K.; Wesselink, P.R. An evaluation of the influence of passive ultrasonic irrigation on the seal of root canal fillings. Int. Endod. J. 2007, 40, 356-361. [CrossRef] [PubMed]

15. Harrison, A.J.; Chivatxaranukul, P.; Parashos, P.; Messer, H.H. The effect of ultrasonically activated irrigation on reduction of Enterococcus faecalis in experimentally infected root canals. Int. Endod. J. 2010, 43, 968-977. [CrossRef] [PubMed]

16. Freire, L.G.; Iglecias, E.F.; Cunha, R.S.; Dos Santos, M.; Gavini, G. Micro-Computed Tomographic Evaluation of Hard Tissue Debris Removal after Different Irrigation Methods and Its Influence on the Filling of Curved Canals. J. Endod. 2015, 41, 1660-1666. [CrossRef] [PubMed] 
17. Leoni, G.B.; Versiani, M.A.; Silva-Sousa, Y.T.; Bruniera, J.F.; Pecora, J.D.; Sousa-Neto, M.D. Ex vivo evaluation of four final irrigation protocols on the removal of hard-tissue debris from the mesial root canal system of mandibular first molars. Int. Endod. J. 2017, 50, 398-406. [CrossRef] [PubMed]

18. Lee, O.Y.S.; Khan, K.; Li, K.Y.; Shetty, H.; Abiad, R.S.; Cheung, G.S.P.; Neelakantan, P. Influence of apical preparation size and irrigation technique on root canal debridement: A histological analysis of round and oval root canals. Int. Endod. J. 2019, 52, 1366-1376. [CrossRef] [PubMed]

19. Schneider, S.W. A comparison of canal preparations in straight and curved root canals. Oral Surg. Oral Med. Oral Pathol. 1971, 32, 271-275. [CrossRef]

20. Langeland, K.; Liao, K.; Pascon, E.A. Work-saving devices in endodontics: Efficacy of sonic and ultrasonic techniques. J. Endod. 1985, 11, 499-510. [CrossRef]

21. Siqueira, J.F., Jr.; Araujo, M.C.; Garcia, P.F.; Fraga, R.C.; Dantas, C.J. Histological evaluation of the effectiveness of five instrumentation techniques for cleaning the apical third of root canals. J. Endod. 1997, 23, 499-502. [CrossRef]

22. Goerg, S.J.; Kaiser, J. Nonparametric Testing of Distributions-The Epps-Singleton Two-Sample Test using the Empirical Characteristic Function. Stata. J. 2009, 3, 454-465. [CrossRef]

23. Clarke, K.R. Nonparametric Multivariate Analyses of Changes in Community Structure. Austral Ecol. 1993, 18, 117-143. [CrossRef]

24. Hammer, O.; Harper, D.A.T.; Ryan, P.D. PAST: Paleontological Statistics Software Package for Education and Data Analysis. Palaeontol. Electron. 2001, 4, e9.

25. Rodrigues, R.C.V.; Zandi, H.; Kristoffersen, A.K.; Enersen, M.; Mdala, I.; Orstavik, D.; Rocas, I.N.; Siqueira, J.F., Jr. Influence of the Apical Preparation Size and the Irrigant Type on Bacterial Reduction in Root Canal-treated Teeth with Apical Periodontitis. J. Endod. 2017, 43, 1058-1063. [CrossRef]

26. Usman, N.; Baumgartner, J.C.; Marshall, J.G. Influence of instrument size on root canal debridement. J. Endod. 2004, 30, 110-112. [CrossRef] [PubMed]

27. Albrecht, L.J.; Baumgartner, J.C.; Marshall, J.G. Evaluation of apical debris removal using various sizes and tapers of ProFile GT files. J. Endod. 2004, 30, 425-428. [CrossRef] [PubMed]

28. Dalton, B.C.; Orstavik, D.; Phillips, C.; Pettiette, M.; Trope, M. Bacterial reduction with nickel-titanium rotary instrumentation. J. Endod. 1998, 24, 763-767. [CrossRef]

29. Plotino, G.; Grande, N.M.; Tocci, L.; Testarelli, L.; Gambarini, G. Influence of Different Apical Preparations on Root Canal Cleanliness in Human Molars: A SEM Study. J. Oral Maxillofac. Res. 2014, 5, e4. [CrossRef]

30. Xu, K.; Wang, J.; Wang, K.; Gen, N.; Li, J. Micro-computed tomographic evaluation of the effect of the final apical size prepared by rotary nickel-titanium files on the removal efficacy of hard-tissue debris. J. Int. Med. Res. 2018, 46, 2219-2229. [CrossRef] [PubMed]

31. Paque, F.; Musch, U.; Hulsmann, M. Comparison of root canal preparation using RaCe and ProTaper rotary Ni-Ti instruments. Int. Endod. J. 2005, 38, 8-16. [CrossRef] 